How to cite this article:

Razi, M. J. M., \& Habibullah, M., \& Hussin, H. (2019). Knowledge management behavior among academicians: The case of a Malaysian higher learning institution. Journal of Information and Communication Technology, 18(2), 183-206.

\title{
KNOWLEDGE MANAGEMENT BEHAVIOR AMONG ACADEMICIANS: THE CASE OF A MALAYSIAN HIGHER LEARNING INSTITUTION
}

\author{
${ }^{1}$ Mohamed Jalaldeen Mohamed Razi, ${ }^{2}$ Md Habibullah \& \\ ${ }^{3}$ Husnayati Hussin \\ ${ }^{1}$ Department of Commerce and Financial Management, \\ University of Kelaniya, Sri Lanka \\ ${ }^{2}$ Department of Computer Science and Engineering, Uttara University, \\ Bangladesh \\ ${ }^{3}$ Department of Information Systems, International Islamic University \\ Malaysia, Malaysia
}

razim@kln.ac.lk; hadi691@gmail.com;husnayati@iium.edu.my

\begin{abstract}
Proper knowledge management $(\mathrm{KM})$ is vital for any organization to perform to the expectation including higher learning institutions (HLIs). Hence, struggling to perform is an indication of lack of KM initiatives. Though many facets of KM have been investigated in HLIs, more studies are needed as the previous empirical works have focused only on knowledge sharing behavior among academicians. An intensive literature review exposes that nonexistence of works employing KM-related theories. Therefore, this study seeks to investigate academicians' perceived intention (KM Intention) and involvement in $\mathrm{KM}$ initiatives (KM Behavior) and its predictors in a Malaysian HLI, which is struggling to perform, by relating theory of knowledge creation. KM intention explains the perception and the attitudes towards KM while the KM behavior illustrates the real behavior. Both these variables were operationalized based on knowledge creation theory through the socialization, externalization, combination, and internalization (SECI) process. A conceptual
\end{abstract}


framework was developed based on the theory of reasoned action and the theory of planned behavior. Six independent variables representative of the socio-cultural nature of $\mathrm{KM}$ - trust, management support, decentralization, IT support, performance expectancy, and effort expectancy - were considered as the predictors of KM intention, which in turn, predict $\mathrm{KM}$ behavior. Data were collected from 156 academicians from an HLI in Malaysia using questionnaires. The questionnaire items were adapted from previous studies. The structural model analysis confirmed that out of seven proposed hypotheses, four are supported: Trust, performance expectancy, and effort expectancy influence KM Intention, while KM Intention influences KM Behavior. Even though further research works are needed to generalize the findings, the current research and the findings can enrich the KM literature and provide some insights to the decision makers of the selected HLI on the appropriate KM implementation strategies.

Keywords: Knowledge management, knowledge sharing behavior, faculty members, theory of reasoned action, theory of planned behavior

\section{INTRODUCTION}

Knowledge management (KM) has been recognized as one of the critical elements of organizational success and an enabler of competitiveness in local and global contexts (Behringer \& Sassenberg, 2015; Pawlowski \& Bick, 2015). Consequently, the concept of KM gets much attention from both academicians and the corporate world (Donate \& Pablo, 2015). Thus, KM as a discipline is proliferating and progressing from an established academic discipline (Donate $\&$ Pablo, 2015) to a reference discipline (Serenko \& Bontis, 2013). A variety of topics, from foundational issues such as KM implementation and adoption processes (Pawlowski \& Bick, 2015) to empirical examination of the link between KM and firm performance (Cohen \& Olsen, 2015), has emerged in the field to understand KM including in higher learning institutions (HLI) in different countries.

Like any other organizations, HLIs are highly dependent on KM behavior among their members, especially academicians, for their overall successful performance (Ramachandran, Chong, \& Wong, 2013; Ramayah, Yeap, \& Ignatius, 2014; Sohail \& Daud, 2009; Tan \& Noor, 2013; Kashim, Kasim, \& 
Rahman, 2018). As members of an HLI, academicians have an obligatory duty to create knowledge through research and intuitions and disseminate (share) that knowledge to students, colleagues and the society (Ramayah et al., 2014). In the HLI context, research and development are considered an example of knowledge creation (KC) activity, while publications, presentations, websites, white papers, teaching and learning activities, policies, and reports are some mechanisms used for knowledge sharing (KS) or knowledge dissemination (Ramachandran et al., 2013), thus the academicians are considered as knowledge creators and knowledge disseminators. As such, better KM practices will certainly help the development of quality education and improve the performance of an organization and the society at large (Jolaee, Nor, Khani, \& Yusoff, 2014).

The HLI under consideration for this study is struggling to maintain the required level of research outputs and publications set by the Malaysian Research Assessment Instrument (MYRA). The same struggle can be a common problem among other HLIs as well. Among the different kinds of factors which are believed to be the cause for the debacle, the current researchers believe that lack of KM behavior among the academicians might be a significant aspect as there are studies that link KM and HLI's performance (Mohayidin, Azirawani, Kamaruddin, \& Margono, 2007; Naser, Al Shobaki, \& Amuna, 2016). Therefore, the primary objective of this study to understand the KM intention and KM behavior of the academicians of this selected HLI and the factors that influence their intention and behavior. The researchers believe that this research findings might be useful to the management of the selected HLI and to other HLIs, in general, to formulate proper strategies of KM.

Most past studies in the Malaysian HLI context focus on knowledge sharing behavior among academicians (Ramachandran et al., 2013; Jain, Sandhu, \& Sidhu, 2007; Jolaee et al., 2014; Mahmoud, Rasli, Othman, \& Abdulahad, 2014; Ramayah et al., 2014 ; Sohail \& Daud, 2009; Tan \& Noor, 2013; Wei Chong, Yen Yuen, \& Chew Gan, 2014) and non-academic staff (Rahman, Osmangani, Daud, \& AbdelFattah, 2016). Though academicians' KM behavior has been investigated extensively in the recent past, it is believed more studies are still needed in this area of KM (Ramachandran et al., 2013), especially empirical studies involving academicians in Malaysia (Jolaee et al., 2014). Furthermore, the government of Malaysia expects the fullest support of HLIs to transform the economy from industrial based to knowledge-based and finally achieve its K-economy strategy master plan goals (Mahmoud et al., 2014; Wei Chong et al., 2014). 
Therefore, it is imperative to understand the level of involvement in KM behavior by academicians and the factors that influence such behavior for KM project success (Jolaee et al., 2014; Sohail \& Daud, 2009), especially in the Malaysian context as not many studies based on Malaysia are available in this area of KM (Jolaee et al., 2014; Wei Chong et al., 2014). Most previous studies focused only on KS aspects investigating organizational factors that support or inhibit KM or KS practices, and do not go in deep to understand the primary initiatives of KM (i.e. the socialization, externalization, combination, and internalization (SECI) process). The main aim of this study is to investigate the KM behavior and its predictors among university academicians within the prevailing organizational climate in a Malaysian HLI. The current study focuses on both $\mathrm{KC}$ and $\mathrm{KS}$ behavior and defines $\mathrm{KM}$ behavior as the involvement in the $\mathrm{KM}$ process ( $\mathrm{KC}$ and $\mathrm{KS}$ ) by the organizational individuals (academicians) within the prevailing organizational (university) climate (context) (Razi, Karim, \& Mohamed, 2011). To reflect KC and KS, the KM has been operationalized based on SECI process, the outcome of knowledge creation theory (Nonaka, Byosiere, Borucki, \& Konno, 1994), which is considered as the essential initiatives for $\mathrm{KC}$ and $\mathrm{KS}$ (BecerraFernandez, Gonzalez, \& Sabherwal, 2004; Lee \& Choi, 2003; Teerajetgul \& Charoenngam, 2006).

The SECI process comprises of socialization, externalization, combination, and internalization. They are the elements of knowledge creation theory that posit an organization, creates knowledge through interactions between explicit knowledge and tacit knowledge (Nonaka et al., 1994), and the knowledge grows in both quality and quantity during this process of knowledge conversion (Esterhuizen, Schutte, \& Toit, 2012). Esterhuizen et al. (2012) explain the SECI process as the process of tacit knowledge transfers to tacit knowledge called socialization. As tacit knowledge is time and space specific, and difficult to formalize, it can be converted and shared through shared experience. Similarly, the process of explicit knowledge transfer to tacit knowledge is called externalization. Knowledge is formed when tacit knowledge is articulated into explicit knowledge. This allows it to be shared by others, and it then becomes the basis of new knowledge. The process of transferring explicit knowledge to more complex and systematic sets of explicit knowledge is known as the combination. Explicit knowledge is gathered internally, or externally, and then combined, edited or processed to form new knowledge, which is then disseminated to the members of the enterprise. Likewise, the process of explicit to tacit knowledge transfer is considered as internalization, which is closely related to 'learning by doing.' 
Created explicit knowledge is shared throughout an enterprise and converted into tacit knowledge by individuals as they embody it.

Therefore, this study aims to understand the KM behavior and its predictors among academicians in an HLI in Malaysia by operationalizing the KM behavior through the SECI process, which is considered as the routing process of KM in an organizational context (Nonaka et al., 1994). Indeed, there was a similar kind of effort (Razi et al., 2011) employed among academicians previously. However, it only measures the intention towards KM. In this work, we go beyond the perceived intention to actual behavior.

As a novel contribution, this study might be among the pioneer works to operationalize the KM intention and KM behavior through knowledge creation theory (i.e., SECI process) and to propose a research instrument to that effect. Similarly, the incorporation of individual acceptance factors; performance expectancy of KM and effort expectancy of KM adapted from the unified theory of acceptance and use of technology (UTAUT) as predictors of KM intention and KM behavior, might be another novel contribution as most of the previous work considered only the organizational factors as the predictors. The instrument formed and validated in this research can be used as a research tool in future works to explore more on KM behavior in organizations. The subsequent section explains previous related work.

\section{RELATED WORK}

As mentioned in the preceding section, most of the related previous studies on Malaysian context concentrated on KS in HLIs. Some studies focused on barriers to KS. For example, the work of Jain et al. (2007) focused on knowledge sharing activities among academicians in Business Schools in the Klang Valley. This research especially focused on barriers that exist in knowledge sharing in an academic environment. Other studies such as Sohail and Daud (2009) examined the factors and barriers that contribute to successful knowledge sharing among academicians from economics and business management departments of HLIs from both public and private universities and colleges in Malaysia. The factors considered include the nature of knowledge, working culture, staff attitudes, motivation to share and opportunities to share. Similarly, Wei Chong et al. (2014) explored the KS barriers and strategies of academicians in public and private universities in Malaysia. 
Some researchers focused on the impact of organizational culture on KS. Mahmoud et al. (2014) had investigated the level of KS among academicians from Universiti Teknologi Malaysia who hold administrative positions and KS predictors from the organizational cultural perspective considering workgroup support, reward system, social interaction, and information technology. A few others such as Tan and Noor (2013) investigated the impact of KM enablers (i.e. trust, knowledge self-efficacy, reciprocal benefits, top management support, organizational rewards, organizational culture, KM system infrastructure and KM system quality, openness in communication, and face-to-face interactive communication) on KS that supports research collaboration by academicians in research universities in Malaysia.

Some researchers focused on KS intention. Jolaee et al. (2014) investigated factors affecting knowledge-sharing intention among academicians in three social science faculties in one public university in Malaysia utilizing the theory of reasoned action (TRA) as the underlying research framework. Similarly, the work of Razi et al. (2011) focused on KM intention among academicians of a public university.

Different approaches can be witnessed in the related literature on this study. Ramayah et al. (2014) validated a previously used Knowledge Sharing Behavior Scale (KSBS) by collecting data from academicians from the arts and science disciplines in public universities in Malaysia. The KSBS focused on written contributions, organizational communications, and personal interactions in the communities of practice, organizational commitment, organizational citizenship behavior, and KS. On the other hand, Ramachandran et al. (2013) examined the gap between KM practices and key strategic enablers in four public universities that fall under the Malaysian Technical University Network based on two dimensions: use and importance. For them, knowledge practices consist of a series of processes by which the knowledge of academicians is generated, captured, codified, stored, shared, and applied. The implementation of these practices is supported by a series of vital strategic enablers such as strategy and leadership, organizational culture, IT, and performance measurement.

As a summary, most of the related works in Malaysian context concentrated on $\mathrm{KS}$ and adopted a survey-based research approach. However, it is tough to find a work based on KM-related theories such as the theory of knowledge creation. In this background, the present study aims to explore the KM behavior among academicians in a public university in Malaysia from different perspectives. First, the concentration is on KM that includes both KC and KS. Second, the $\mathrm{KM}$ intention and $\mathrm{KM}$ behavior are operationalized to the root processes 
of KM, i.e., SECI process adapted from knowledge creation theory. Third, the study extends beyond the KM intention to KM behavior based on TRA and TPB. Fourth, in addition to KM supportive organizational factors (KM enablers, or organizational climate), the current work considers individual acceptance factors adapted from UTAUT, i.e., performance expectancy (PE) and effort expectancy (EE) of KM as the predictors of KM behavior.

\section{METHODS}

The conceptual framework for this study was developed based on the TRA (Fishbein \& Ajzen, 1975) and the TPB (Ajzen, 1991), which posits human intention will lead to their behavior. The conceptual model was operationalized by previous related studies (Choi, Kang, \& Lee, 2008; Lee \& Choi, 2003; Lin, 2007; Meirovich, Brender-Ilan, \& Meirovich, 2007; Venkatesh, Morris, Davis, \& Davis, 2003). For this study, the KM behavior refers to the involvement in the SECI process by the academicians within the current university cultural, structural and technical context. The socialization process refers to the conversion of tacit knowledge to new tacit knowledge through social interactions and shared experience among academicians (Alavi \& Leidner, 2001), while externalization means the expression of tacit knowledge and its conversion into comprehensible forms that are easier to understand (Becerra-Fernandez \& Sabherwal, 2001). Similarly, the combination process collects explicit knowledge from inside or outside the organization and then combines, edits, or processes it to form more complex and systematic explicit knowledge. On the other hand, internalization can be understood as praxis, where knowledge is applied and used in practical situations and becomes the base for new routines (Nonaka \& Toyama, 2003).

Trust among colleagues, top management support, decentralization of decision-making process, and availability of Information Technology (IT) support are considered as the elements of organizational climate. To denote individual acceptance, PE and EE of KM were incorporated.

Trust refers to the degree of reciprocal faith among the colleagues concerning intention and behavior within the organization (Choi et al., 2008). A positive relationship between trust and KM has been established (Chen \& Hung, 2010; Lee, Shiue, \& Chen, 2016; Lee \& Lan, 2011) including in academic setups (Tan \& Noor, 2013). Therefore, we propose the following hypothesis.

H1: Trust will positively influence KM intention. 
Management support means the degree of support from top managers for KM by providing guidance and necessary resources (Lin, 2007). The effect of management support and KM oriented leadership towards KM behavior has been elaborated (Donate \& Pablo, 2015; Lee et al., 2016; Pawlowski \& Bick, 2015), including in HLI context (Ramachandran et al., 2013). Hence, we propose the following hypothesis.

H2: Management Support will positively influence KM intention.

Decentralization refers to a management structure that emphasizes employee autonomy and participation in decision-making (Meirovich et al., 2007). The positive effects of decentralization on $\mathrm{KM}$ intention/KM behavior have been recognized in the literature (Chen \& Huang, 2007; Willem \& Buelens, 2009). Thus, we suggest the following relationship.

H3: Decentralization will positively influence KM intention.

IT Support denotes the degree of availability of IT support for KM process initiatives within the organization (Lee \& Choi, 2003). The relationship between IT and KM behavior has been well explained (Cohen \& Olsen, 2015; Teerajetgul \& Charoenngam, 2006) including in the academic environment (Ramachandran et al., 2013; Mahmoud et al., 2014; Razi et al., 2011). Therefore, we have no hesitation to propose as follows.

H4: IT Support will positively influence KM Intention.

PE of KM means the degree to which an individual believes that involvement in $\mathrm{KM}$ processes will help him/her to attain gains in job performance (Venkatesh et al., 2003). The works of Behringer and Sassenberg (2015), Li (2010) and Razi et al. (2011) suggest the following relationship.

H5: PE of KM will positively influence KM Intention.

EE of KM explains the degree of ease associated with the involvement in KM process (Venkatesh et al., 2003). The influence of effort expectancy on behavior is obvious (Venkatesh et al., 2003), and as such we propose the following hypothesis.

H6: EE of KM will positively influence KM intention.

Based on TRA (Fishbein \& Ajzen, 1975) and TPB (Ajzen, 1991), the following hypothesis was formulated. 
H7: KM intention will positively influence $\mathrm{KM}$ behavior.

Following the arguments mentioned above, a hypothetical research model was developed as shown in Figure 1.

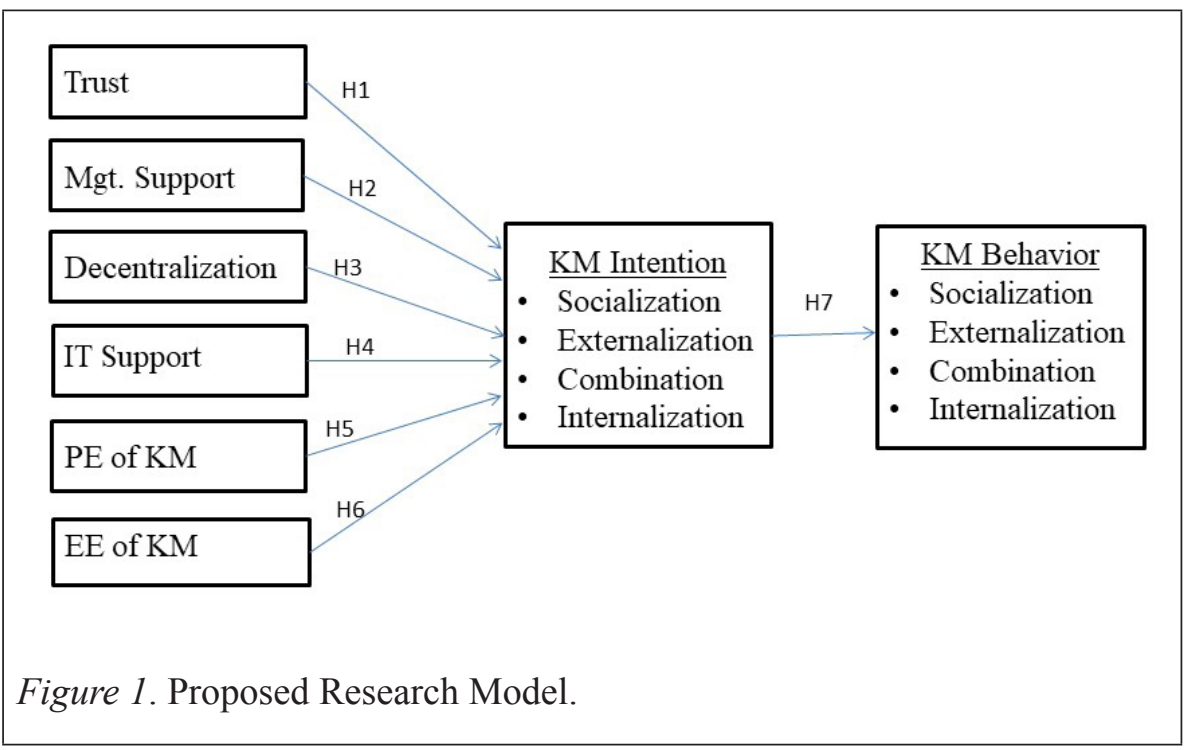

A questionnaire was developed as the research instrument which consists of four sections and preceded by a covering letter. Part I requests respondents to provide brief background information which entails academic position, gender, academic field, and nationality. All the questions were resented in category scales, and the respondents were requested to tick on the appropriate boxes. Part II captures the respondents' KM intention while Part III captures the perceived organizational climate, and part IV captures the KM behavior of respondents. Other than the background information, all other measures used the following seven levels of Likert scale: (1) strongly disagree, (2) disagree, (3) slightly disagree, (4) neutral, (5) slightly agree, (6) agree, and (7) strongly agree. The questionnaire used was initially pre-tested with few subject experts, academic staff, and Ph.D. candidates. They were requested to evaluate and appraise the questionnaire regarding content accuracy, clarity, length, and overall presentation. Besides, a pilot study was conducted among 45 academic staff with the purpose of measuring the reliability of the instrument. Based on the comments and the results of the above procedures the questionnaire was modified. Notably, the items to measure decentralization were replaced with new items from a different source. The final survey items are shown in Table. 


\section{Table 1}

\section{Research Instrument}

\begin{tabular}{|c|c|c|c|}
\hline Construct & Code & Questions & Source \\
\hline \multirow{4}{*}{ Trust } & Trust1 & $\begin{array}{l}\text { I believe colleagues in my organization are honest } \\
\text { and reliable }\end{array}$ & \multirow{4}{*}{$\begin{array}{c}\text { (Choi et al. } \\
\text { 2008) }\end{array}$} \\
\hline & Trust2 & $\begin{array}{l}\text { I believe colleagues in my organization treat other } \\
\text { reciprocally }\end{array}$ & \\
\hline & Trust3 & $\begin{array}{l}\text { I believe colleagues in my organization are } \\
\text { knowledgeable and competent in their area. }\end{array}$ & \\
\hline & Trust4 & $\begin{array}{l}\text { I believe colleagues in my organization will act } \\
\text { towards the best interest of the organizational } \\
\text { goals. }\end{array}$ & \\
\hline \multirow{3}{*}{ Mgt. Support } & MGT1 & $\begin{array}{l}\text { My senior managers always support the } \\
\text { knowledge creation and sharing initiatives. }\end{array}$ & \multirow{3}{*}{ (Lin, 2007) } \\
\hline & MGT2 & $\begin{array}{l}\text { My senior managers provide necessary help and } \\
\text { resources for knowledge creation and sharing } \\
\text { initiatives. }\end{array}$ & \\
\hline & MGT3 & $\begin{array}{l}\text { My senior managers are keen to see my } \\
\text { involvement in knowledge creation and sharing } \\
\text { initiatives. }\end{array}$ & \\
\hline
\end{tabular}

Dec.1 The individual decision maker has wide freedom in the choice of means to accomplish organizational goals.

Dec.2 Employees have substantial autonomy when

Decentralization performing their job.

Dec.3 Many important decisions are made locally rather al., 2007) than centrally.

Dec.4 The employees participate in the decision-making process.
ITS1 My organization provides IT support for collaborative works regardless of time and place.

ITS2 My organization provides IT support for communication among colleagues in my

IT Support organization

(Lee \& Choi, 2003)

ITS3 My organization provides IT support for systematic storing of valuable records.

ITS4 My organization provides IT support for searching necessary information and sharing it with others 


\begin{tabular}{cclc}
\hline Construct & Code & \multicolumn{1}{c}{ Questions } & Source \\
\hline & PE1 & $\begin{array}{l}\text { I would find creation and sharing of knowledge } \\
\text { useful in my job. }\end{array}$ & \\
& PE2 & $\begin{array}{l}\text { Creation and sharing of knowledge would enable } \\
\text { me to accomplish the task more quickly. }\end{array}$ & \\
PE of KM & PE3 & $\begin{array}{l}\text { If I involve with knowledge creation and sharing } \\
\text { initiatives, it will increase my chances of getting } \\
\text { better pay. } \\
\text { (Venkatesh et } \\
\text { al., 2003) } \\
\text { my productivity. }\end{array}$ & \\
& PE4 & & \\
\end{tabular}

EE1 My role in knowledge creation and sharing process would be clear and understandable.

EE2 It would be easy for me to become skillful in knowledge creation and sharing initiatives.

EE of KM

EE3 Learning the initiatives of creation and sharing of knowledge would be easy for me.

(Venkatesh et al., 2003)

EE4 I would find the involvement in the process of knowledge creation, and share be easy

SOC1I I intend to be involved in gathering knowledge and experiences from others in my organization.

SOC2I I intend to be involved in sharing knowledge and experiences with others in my organization.

SOC3I I intend to be involved in finding new strategies and opportunities inside the organization.

SOC4I I intend to be involved in creating a work environment that allows colleagues to understand the craftsmanship and expertise.

Lee \& Choi,

KM Intention

EXT1I I intend to be involved in creative dialogues with 2003) colleagues.

EXT2I I intend to use deductive (top-down) and inductive (bottom-up) thinking for strategy formulation.

EXT3I I intend to exchange various ideas with colleagues.

EXT4I I intend to provide subjective opinions in dialogues. 


\begin{tabular}{|c|c|c|c|}
\hline Construct & Code & Questions & Source \\
\hline & COM1I & $\begin{array}{l}\text { I intend to use published literature, computer } \\
\text { simulation and forecasting to formulate strategies. }\end{array}$ & \\
\hline & COM2I & $\begin{array}{l}\text { I intend to create documents/databases on my } \\
\text { courses. }\end{array}$ & \\
\hline & COM3I & $\begin{array}{l}\text { I intend to build up materials by gathering } \\
\text { literature and technical information. }\end{array}$ & \\
\hline & COM4I & $\begin{array}{l}\text { I intend to transfer newly created concepts to my } \\
\text { colleagues }\end{array}$ & \\
\hline & INT1I & $\begin{array}{l}\text { I intend to be involved in liaising activities with } \\
\text { other departments by developing cross-functional } \\
\text { teams. }\end{array}$ & \\
\hline & INT2I & $\begin{array}{l}\text { I intend to be involved in setting teams as a model } \\
\text { for conducting experiments and sharing results } \\
\text { with entire departments. }\end{array}$ & \\
\hline & INT3I & $\begin{array}{l}\text { I intend to be involved in searching and sharing } \\
\text { new values and thoughts with colleagues. }\end{array}$ & \\
\hline & INT4I & $\begin{array}{l}\text { I intend to share and try to understand } \\
\text { management vision through communications with } \\
\text { colleagues. }\end{array}$ & \\
\hline
\end{tabular}

SOC1B I involve in gathering knowledge and experiences from others in my organization.

SOC2B I involve in sharing knowledge and experiences with others within my organization.

SOC3B I involve in finding new strategies and opportunities inside the organization.

SOC4B I involve in creating a work environment that allows colleagues to understand the craftsmanship and expertise.

SOC1B I involve in gathering knowledge and experiences from others in my organization.

(Lee \& Choi, 2003)

SOC2B I involve in sharing knowledge and experiences with others within my organization.

SOC3B I involve in finding new strategies and opportunities inside the organization.

SOC4B I involve in creating a work environment that allows colleagues to understand the craftsmanship and expertise.

COM1B I use published literature, computer simulation and forecasting to formulate strategies.

COM2B I create manuals and documents on my courses. 


\begin{tabular}{lll}
\hline Construct & Code & \multicolumn{1}{c}{ Questions } \\
\hline & COM3B & $\begin{array}{l}\text { I build up materials by gathering literature and } \\
\text { technical information. }\end{array}$ \\
COM4B & I transfer newly created concepts to my colleagues \\
INT1B & $\begin{array}{l}\text { I involve in liaising activities with other } \\
\text { departments by developing cross-functional teams. } \\
\text { INT2B }\end{array}$ & $\begin{array}{l}\text { I involve in setting teams as a model for } \\
\text { conducting experiments and sharing results with } \\
\text { entire departments. }\end{array}$ \\
INT3B & $\begin{array}{l}\text { I involve in searching and sharing new values and } \\
\text { thoughts with colleagues. } \\
\text { INT4B }\end{array}$ & $\begin{array}{l}\text { I share and try to understand management vision } \\
\text { through communications with colleagues. }\end{array}$ \\
\hline
\end{tabular}

400 paper-based questionnaires were distributed among the academic staff by visiting their office by a research assistant. He reminded the respondents from time to time. The data collection period expanded for about three months. Finally, 156 usable responds were received. Out of 156 respondents, 24 (15.4\%) were Professors, 36 (23.1\%) Associate Professors, 56 (35.9) Assistant Professors, and 40 (25.6\%) lecturers. Gender wise, 90 (57.7\%) were males, and the rest $(66 ; 42.3 \%)$ were females. Regarding the nature of their academic field, $97(62.2 \%)$ were from social science faculties while the rest $(59 ; 37.8 \%)$ were from science and technology faculties. Concerning nationality, 90 $(57.7 \%)$ were locals, while $66(42.3 \%)$ were international.

SPSS 16 was used for descriptive statistics analysis while SmartPLS 3.0 was used for measurement model analysis and structural model analysis. The measurement model was evaluated using internal consistency reliability, indicator reliability, convergent reliability, and discriminant validity. The coefficient of determination $\left(\mathrm{R}^{2}\right)$ and path coefficients was evaluated in a structural model assessment.

\section{RESULTS}

The study adopted a two-step process as suggested by Hair and Hult (2016) to assess the measurement model and the structural model. The first step involved assessing the measurement model by running algorithm in SmartPLS 3.0. Figure 2 depicts the measurement model after deleting the items that did not meet the factor loading threshold value of 0.45 as suggested by Hair and Hult (2016) for the sample size of 156. The deleted items are PE3, SOC2I, EXT2B, EXT3B, and EXT4B. 


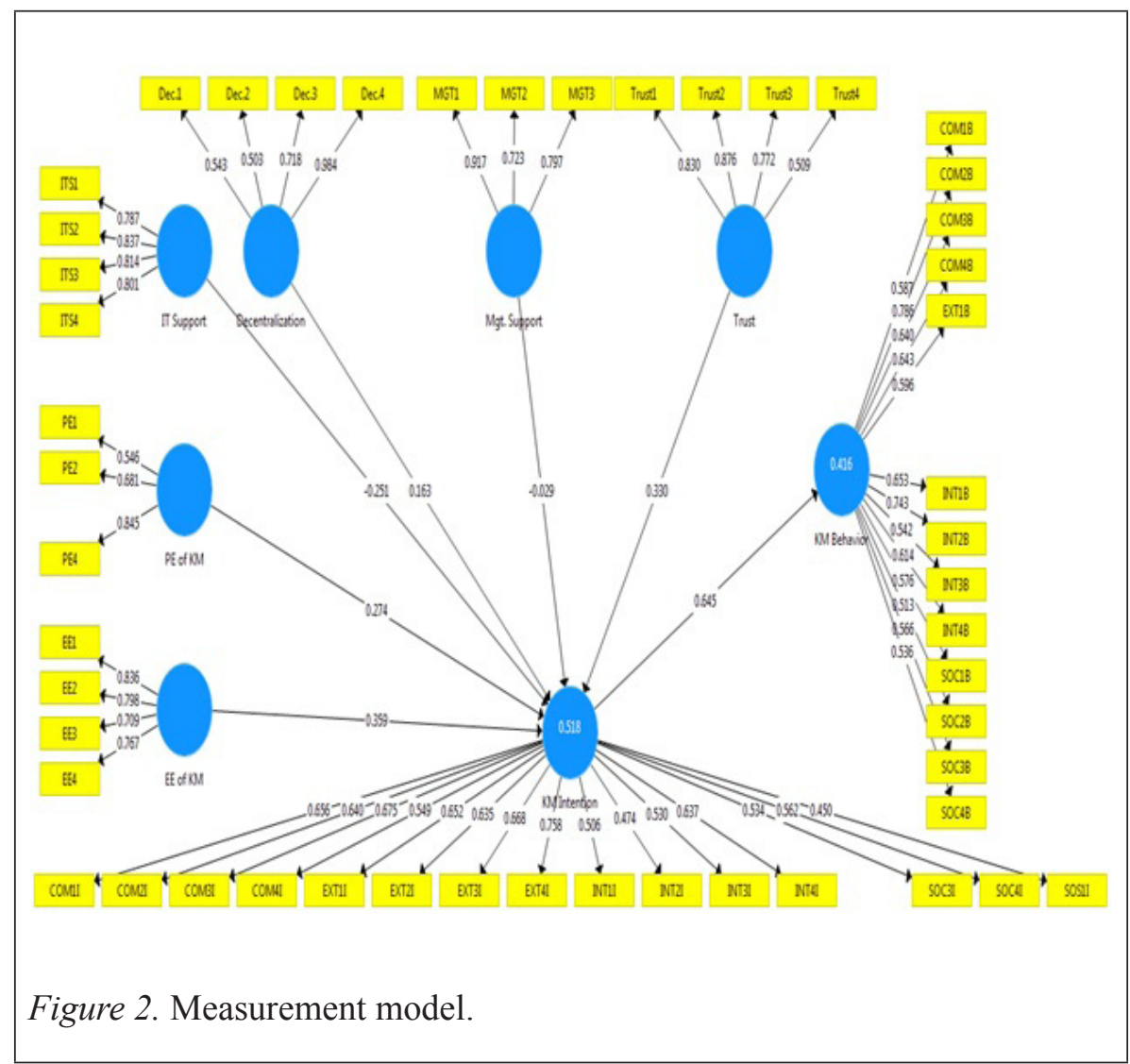

Table 2 shows the factor loading values of each item, and Cronbach's Alpha, Composite reliability, and average variance extracted (AVE) values for each variable. The Cronbach's Alpha values were higher than the threshold value of 0.7 except for PE of KM. However, the CR value for PE of KM was 0.738 (higher than the threshold value of 0.7) even though the AVE was less than the threshold value of 0.5 . Since the variable PE of KM is one of the central constructs in this research and deletion of any item did not improve the Alpha value or AVE, we decided to keep the construct for further analysis following the suggestion of Hair and Hult (2016). Similarly, the AVE value for KM intention and KM behavior were also less than 0.5. However, the Alpha and $\mathrm{CR}$ values were acceptable. Therefore, the constructs were retained for further analysis following the suggestion by Hair and Hult (2016) for the same reason.

The correlations and discriminant validity are shown in Table 3. The discriminant validity was assessed by using Fornell and Larcker's criterion. The square root of AVE should exceed the correlations between the measurement 
Table 2

Factor Loadings, Cronbach's Alpha, Composite Reliability and Average Variance Extracted

\begin{tabular}{|c|c|c|c|c|c|}
\hline Construct & $\begin{array}{l}\text { Measurement } \\
\text { Items }\end{array}$ & Loadings & $\begin{array}{l}\text { Cronbach's } \\
\text { Alpha }\end{array}$ & $\mathrm{CR}$ & AVE \\
\hline Trust & $\begin{array}{l}\text { Trust1, Trust2, } \\
\text { Trust3, Trust4 }\end{array}$ & $\begin{array}{c}0.830,0.876 \\
0.772,0.509\end{array}$ & 0.748 & 0.841 & 0.578 \\
\hline Mgt. Support & $\begin{array}{c}\text { MGT1, MGT2, } \\
\text { MGT3 }\end{array}$ & $\begin{array}{c}0.917,0.723 \\
0.797\end{array}$ & 0.783 & 0.856 & 0.666 \\
\hline Decentralization & $\begin{array}{c}\text { Dec.1, Dec.2, } \\
\text { Dec.3, Dec. } 4\end{array}$ & $\begin{array}{c}0.543,0.503 \\
0.718,0.984\end{array}$ & 0.824 & 0.793 & 0.508 \\
\hline IT Support & $\begin{array}{l}\text { ITS1, ITS2, } \\
\text { ITS3, ITS4 }\end{array}$ & $\begin{array}{c}0.787,0.837 \\
0.814,0.801\end{array}$ & 0.825 & 0.884 & 0.656 \\
\hline PE of KM & $\begin{array}{l}\text { PE1, PE2, } \\
\text { PE4 }\end{array}$ & $\begin{array}{c}0.546,0.681 \\
0.845\end{array}$ & 0.533 & 0.738 & 0.492 \\
\hline $\mathrm{EE}$ of $\mathrm{KM}$ & $\begin{array}{l}\text { EE1, EE2, } \\
\text { EE3, EE4 }\end{array}$ & $\begin{array}{c}0.836,0.798 \\
0.709,0.767\end{array}$ & 0.785 & 0.860 & 0.607 \\
\hline KM Intention & $\begin{array}{c}\text { SOC1I, } \\
\text { SOC3I, SOC4I } \\
\text { EXT1I, EXT2I, } \\
\text { EXT3I, EXT4I } \\
\text { COM1I, COM2I, } \\
\text { COM3I, COM4I } \\
\text { INT1I, INT2I, } \\
\text { INT3I, INT4I }\end{array}$ & $\begin{array}{c}0.450, \\
0.534,0.562, \\
0.652,0.635, \\
0.668,0.758, \\
0.656,0.640, \\
0.675,0.549, \\
0.506,0.474, \\
0.530,0.637\end{array}$ & 0.871 & 0.893 & 0.361 \\
\hline KM Behavior & $\begin{array}{c}\text { SOC1B, SOC2B, } \\
\text { SOC3B, SOC4B } \\
\text { EXT1B, } \\
\text { COM1B, COM2B, } \\
\text { COM3B, COM4B } \\
\text { INT1B, INT2B, } \\
\text { INT3B, INT4B }\end{array}$ & $\begin{array}{c}0.576,0.513 \\
0.566,0.536 \\
0.596 \\
0.587,0.786, \\
0.640,0.643, \\
0.653,0.743, \\
0.542,0.614\end{array}$ & 0.864 & 0.889 & 0.384 \\
\hline
\end{tabular}

and all the other measurements, and the indicators' loadings were higher against their construct compared to the other constructs. Accordingly, all constructs except KM behavior satisfied the requirements. The reason for the high correlation between $\mathrm{KM}$ behavior and $\mathrm{KM}$ intention is understandable as the measures (questionnaire items) for both constructs were almost similar. The items for KM intention measured the perceived intention to be involved 
in the SECI process, while the items for KM behavior measured the actual involvement in the SECI process. Therefore, we believe that though there were some discrepancies in reliability and validity test values, in general, the study has proven that all the reliability and validity tests conducted for the measurement model have achieved a satisfactory level.

Table 3

Discriminant Validity

\begin{tabular}{lllllllll}
\hline & Decentralization & $\begin{array}{l}\text { EE of } \\
\text { KM }\end{array}$ & $\begin{array}{l}\text { IT } \\
\text { Support }\end{array}$ & $\begin{array}{l}\text { KM } \\
\text { Behavior }\end{array}$ & $\begin{array}{l}\text { KM } \\
\text { Intention }\end{array}$ & $\begin{array}{l}\text { Mgt. } \\
\text { Support }\end{array}$ & $\begin{array}{l}\text { PE of } \\
\text { KM }\end{array}$ & Trust \\
\hline Decentralization & 0.713 & & & & & & & \\
EE of KM & 0.220 & 0.779 & & & & & & \\
IT Support & 0.682 & 0.273 & 0.810 & & & & & \\
KM Behavior & 0.254 & 0.499 & 0.169 & 0.620 & & & & \\
KM Intention & 0.211 & 0.563 & 0.120 & 0.645 & 0.601 & & & \\
Mgt. Support. & 0.623 & 0.210 & 0.664 & 0.096 & 0.127 & 0.816 & & \\
PE of KM & 0.223 & 0.573 & 0.273 & 0.546 & 0.569 & 0.162 & 0.702 & \\
Trust & 0.294 & 0.260 & 0.325 & 0.451 & 0.486 & 0.308 & 0.384 & 0.760 \\
\hline
\end{tabular}

The descriptive analysis findings reveal that the respondents on average, agreed that they trusted $(\mu=5.93, \sigma=.55)$ their colleagues in the organization and agreed that their top-level managers were very supportive $(\mu=5.77, \sigma=.73)$ for KM behavior. Furthermore, they believed their respective organizations followed decentralized $(\mu=5.76, \sigma=.75)$ decision-making structure and provided enough IT support $(\mu=5.84, \sigma=.72)$ for KM activities. The respondents realized the importance of KM for their performance improvement $(\mu=5.96, \sigma=1.76)$ and believed it needed less effort $(\mu=6.06, \sigma=.50)$ to be involved in KM practices. The essential findings of the descriptive analysis are that the respondents intended to be involved in KM (KM Intention) $(\mu=6.10, \sigma=.41)$, and they practiced KM behavior $(\mu=6.02, \sigma=.47)$ in their work.

Having established the validity and the reliability of the measurement model, to test the hypothesized relationship, bootstrapping (with 500 sub-samples) was performed using SmartPLS 3.0. The predictive relevance of the model, i.e., the quality of the structural model, was assessed by $\mathrm{R}^{2}$. This depicts the variance in the endogenous variables of KM intention and KM behavior. Based on the result reported in Figure $1, \mathrm{R}^{2}$ was found to be 0.518 and 0.416 for $\mathrm{KM}$ intention and $\mathrm{KM}$ behavior respectively. Using the assessment criterion suggested by Cohen, Cohen, West, and Aiken (2013), we concluded that 0.518 
and 0.416 were significant. All the hypotheses were tested by examining the significance of the respective path coefficients. The results are shown in Table 4.

Table 4

Summary of Hypotheses Test

\begin{tabular}{ccccc}
\hline Hypotheses & $\begin{array}{c}\text { Path } \\
\text { Coefficient (b) }\end{array}$ & t Value & p-Value & \\
\hline Trust -> KM Intention (H1) & 0.330 & 4.757 & 0.000 & Supported \\
Mgt. Support -> KM Intention (H2) & -0.029 & 0.299 & 0.765 & Not Supported \\
Decentralization -> KM Intention (H3) & 0.163 & 0.758 & 0.449 & Not Supported \\
IT Support -> KM Intention (H4) & -0.251 & 2.149 & 0.032 & Not Supported \\
PE of KM -> KM Intention (H5) & 0.274 & 3.832 & 0.000 & Supported \\
EE of KM -> KM Intention (H6) & 0.359 & 5.051 & 0.000 & Supported \\
KM Intention -> KM Behavior (H7) & 0.645 & 9.405 & 0.000 & Supported \\
\hline
\end{tabular}

Out of the seven hypotheses proposed, four were supported. Trust (H1), PE of $\mathrm{KM}$ (H5), and EE of KM (H6) positively influence KM intention with positive path coefficient (b) with significant $t$ value at 0.001 confidence level. Even though it was expected that IT support would have a positive influence on KM intention, the result showed a negative $b(-0.251)$ value with significant $t$ value $(\mathrm{t}=2.149, \mathrm{p}=0.032)$. Therefore, the said hypothesis was considered to be not supported. The other two hypotheses ( $\mathrm{H} 2$ and $\mathrm{H} 3)$ were also not supported as the $\mathrm{p}$ values were greater than 0.05 .

\section{DISCUSSION}

The current study provides theoretical and practical insights to understand the $\mathrm{KM}$ intention, $\mathrm{KM}$ behavior and its predictors among academicians in the selected HLI. The findings should also be beneficial to both researchers in the domain of $\mathrm{KM}$ and the practitioners: academic administrators and the policymakers on HLIs in general as well. This study has significantly recognized the positive influence of trust among colleagues on KM intention of academicians $(b=0.330, t=4.757, p=0.000)$. The results suggest that the more the academicians perceive that there is trust among colleagues, the more likely they are to be involved in KM. Theoretically, the finding strengthens the findings of previous studies of Chen and Hung (2010), Lee and Lan (2011), and Tan and Noor (2013). The measures used on trust focused on honesty 
and reliability of colleagues, the expectation of reciprocal treatment, work for the best interest of the organization, and trust in colleagues' knowledge and competency. Therefore, the academic administrators could make an organizational context where the academicians demonstrate the trusting behavior that would eventually lead to trust culture in the organization (university).

The study also recognizes the positive relationship of factors of individual acceptance: performance expectancy of $\mathrm{KM}(\mathrm{b}=0.274, \mathrm{t}=3.832, \mathrm{p}=0.000)$ and effort expectancy of $\mathrm{KM}(\mathrm{b}=0.359, \mathrm{t}=5.051, \mathrm{p}=0.000)$ on $\mathrm{KM}$ intention. The results suggest that the more academicians perceive that KM is useful in doing the job and in improving their productivity, the more likely they are to be involved in KM. Similarly, the more academicians perceive that involving in KM processes is easy, the more likely they are to be involved in KM. Theoretically, these results further strengthen the UTAUT (Venkatesh et al., 2003) in predicting individual behavioral intention and are consistent with previous research work (Behringer \& Sassenberg, 2015; Cimperman, Brenčič, \& Trkman, 2016; Khanam, Mahfuz, \& Ahmed, 2016; Kuciapski, 2017; Li, 2010; Razi et al., 2011).

The scale used for measuring performance expectancy, focused on involvement in $\mathrm{KM}$, which is useful in accomplishing job task and enhancing productivity leading to a better income. Therefore, from a practical point of view, academic administrators could develop an environment in which academicians believe that they could increase their performance if they are involved in it. Perhaps the administrators could create an awareness of how the involvement in KM process will improve the academicians' performance and productivity. At the same time, the administrators could make it clear how the involvement in KM can lead to better pay; i.e., salary increment, bonus or promotion.

The items used for measuring effort expectancy focused on the degree of ease in involving in KM. The scales used to measure effort expectancy focused on ease to learn, be involved and understand the role in the KM process. Since the academicians' job tasks, such as delivering a lecture, involving in research, publishing research findings and mentoring students, are practices of KM in nature, the academic administrators may highlight the ease of involving in $\mathrm{KM}$ and make clear the role expected from each academician for a $\mathrm{KM}$ initiative, if any.

The findings also confirm the positive influence of KM Intention towards KM Behavior $(b=0.645, t=9.405, p=0.000)$ that strengthens the fundamental proposition of TRA (Fishbein \& Ajzen, 1975) and TPB (Ajzen, 1991). 
However, the other three hypotheses were not supported. The findings did not support the significant positive relationship between management support and $\mathrm{KM}$ intention $(\mathrm{b}=-0.029, \mathrm{t}=0.299, \mathrm{p}=0.765)$, which contradicts with some previous works (Ramachandran et al., 2013; Donate \& Pablo, 2015; Lee et al., 2016; Pawlowski \& Bick, 2015) but in line with Tan and Noor (2013). According to the descriptive analysis results, the respondents agreed that their top-level managers were very supportive $(\mu=5.77, \sigma=.73)$ of KM behavior. Thus, the implication here is that the perception of management support did not influence the academicians to be involved in KM. The items used for measuring management support focused on senior managers' support for KM initiatives through the necessary help and resources and their keenness to see the employees' involvement in KM. Academicians, as a subset of knowledge workers, are known to be self-motivated and autonomous, which might have influenced the current findings. With or without the support of the top management, they would still be involved in KM initiatives.

The third hypothesis, decentralization of decision-making positively influences KM intention, was also not supported $(b=0.163, t=0.758, p=$ 0.449) contradicting the findings of Chen and Huang (2007), and Willem and Buelens (2009). The items measuring decentralization focused on freedom in choosing the means of doing the job or autonomy in the job, participation in decision-making, and making the decision locally rather than centrally. The respondents believed that there was decentralized decision-making practiced in the university $(\mu=5.76, \sigma=.75)$. As a common practice in HLIs, academicians enjoy the autonomy in performing their job. Therefore, they might not explicitly see it as an important factor that will encourage them to be involved in KM practices, even though they enjoy the decentralized decisionmaking structure.

The fourth hypothesis, IT support positively influences KM intention, was also not supported $(b=-0.251, t=2.149, p=0.032)$. In fact, the findings show a significant negative relationship $(b=-0.251)$ between IT support and $\mathrm{KM}$ intention, which is not in line with previous studies (Cohen \& Olsen, 2015; Ramachandran et al., 2013; Mahmoud et al., 2014; Razi et al., 2011; Teerajetgul \& Charoenngam, 2006) but support the findings of Tan and Noor (2013). The items that measured IT support concentrated on IT support for collaborative work, communication among colleagues, searching for information and storing valuable information. The nature of academicians' work is in $\mathrm{KM}$ nature, i.e., $\mathrm{KC}$ and $\mathrm{KS}$; conducting research, publishing research findings, involving consultation, delivering lectures, etc. are all in the KM nature. Therefore, the academicians could have confused with the questionnaire items related to IT support and could not find the relevance to 
their day to day activities. Furthermore, there is a myth that students in the class are misusing IT gadgets and IOT (internet of things) (Karim, Zamzuri, \& Nor, 2009) and in their academic work (Hamlen, 2012), which might also have influenced the current findings.

\section{CONCLUSION}

Based on the findings, it can be concluded that the academicians in the HLI selected for this study believed that a trust culture existed among the peers and a decentralized decision-making structure prevailed in the university. They also believed that the top management supports and is committed to KM initiatives and provided the IT support. Also, they believed involvement in KM behavior was easy and useful in their career. Besides, it can be concluded that many academicians perceived that existence of trust among colleagues, the high-performance expectancy of KM and less effort expectancy of KM would more likely influence their involvement in KM.

The present study provides both theoretical and practical contributions to understanding the predictors of KM intention and KM behavior in an HLI context that should be of interest to both academic researchers and academic administrators. For the researchers, the conceptual research framework used in the study can be used to test other settings involving different types of population and sample. For the academic administrators and policymakers, the findings of this study demonstrate that if they are serious to see the academicians involved in KM practices, it is vital to create a trust culture and inform the academicians about the usefulness of KM in improving their job performance, and as such their involvement in KM will be easy and comfortable.

Similar to most of the research works, there are a few limitations related to this study. The respondents (academicians) are limited to one HLI only. Future works should consider extending the scope of the population by considering academicians from other universities. Besides, in addition to the six independent variables considered in this study, a few other variables such as motivational factors, and cultural factors could be examined.

\section{ACKNOWLEDGMENT}

This work has been supported through International Islamic University Malaysia Research Initiative Grant Scheme 2016 (RIGS16-148-0312). 


\section{REFERENCES}

Ajzen, I. (1991). The theory of planned behavior. Organizational Behavior and Human Decision Processes, 50(2), 179-211.

Alavi, M., \& Leidner, D. E. (2001). Review: Knowledge management and knowledge management systems: Conceptual foundations and research issues. MIS Quarterly, 107-136.

Becerra-Fernandez, I., \& Sabherwal, R. (2001). Organizational knowledge management: A contingency perspective. Journal of Management Information Systems, 18(1), 23-55.

Behringer, N., \& Sassenberg, K. (2015). Introducing social media for knowledge management: Determinants of employees' intentions to adopt new tools. Computers in Human Behavior, 48, 290-296.

Chen, C., \& Huang, J. (2007). How organizational climate and structure affect knowledge management. The social interaction perspective. International Journal of Information Management, 27(2), 104-118.

Chen, C., \& Hung, S. (2010). To give or to receive? Factors influencing members' knowledge sharing and community promotion in professional virtual communities. Information \& Management, 47(4), 226-236.

Choi, S. Y., Kang, Y. S., \& Lee, H. (2008). The effects of socio-technical enablers on knowledge sharing: an exploratory examination. Journal of Information Science, 34(5), 742.

Cimperman, M., Brenčič, M. M., \& Trkman, P. (2016). Analyzing older users' home telehealth services acceptance behavior-applying an Extended UTAUT model. International Journal of Medical Informatics, 90, 2231.

Cohen, J., Cohen, P., West, S. G., \& Aiken, L. S. (2013). Applied multiple regression/correlation analysis for the behavioral sciences: Routledge.

Cohen, J. F., \& Olsen, K. (2015). Knowledge management capabilities and firm performance: A test of universalistic, contingency and complementarity perspectives. Expert Systems with Applications, 42(3), 1178-1188.

Donate, M. J., \& de Pablo, J. D. S. (2015). The role of knowledge-oriented leadership in knowledge management practices and innovation. Journal of Business Research, 68(2), 360-370.

Esterhuizen, D., Schutte, C. S., \& Du Toit, A. (2012). Knowledge creation processes as critical enablers for innovation. International Journal of Information Management, 32(4), 354-364.

Fishbein, M., \& Ajzen, I. (1975). Belief, attitude, intention, and behaviour: An introduction to theory and research: Addison-Wesley.

Hair Jr, J. F., \& Hult, G. T. M. (2016). A primer on partial least squares structural equation modeling (PLS-SEM): Sage Publications. 
Hamlen, K. R. (2012). Academic dishonesty and video game play: Is new media use changing conceptions of cheating? Computers \& Education, 59(4), 1145-1152.

Jain, K. K., Sandhu, M. S., \& Sidhu, G. K. (2007). Knowledge sharing among academic staff: A case study of business schools in Klang Valley, Malaysia. Journal for the Advancement of Science and Arts, 2, 23-29.

Jolaee, A., Md Nor, K., Khani, N., \& Md Yusoff, R. (2014). Factors affecting knowledge sharing intention among academic staff. International Journal of Educational Management, 28(4), 413-431.

Karim, N. S. A., Zamzuri, N. H. A., \& Nor, Y. M. (2009). Exploring the relationship between Internet ethics in university students and the big five model of personality. Computers \& Education, 53(1), 86-93.

Khanam,L., Mahfuz, M.A., \&Ahmed,E.(2016). Employee behavioralintention to adopt knowledge management systems (KMS) in Bangladesh. Paper presented at the European Conference on Knowledge Management. Retrieved from https://www.researchgate.net/publication/319620928

Kashim, R., Kasim, M. M., \& Rahman, A. R. (2018). Measuring Efficiency of a university faculty using a hierarchical nework data envelopment analysis model. Journal of ICT, 17(4), 569-585.

Kuciapski, M. (2017). A model of mobile technologies acceptance for knowledge transfer by employees. Journal of Knowledge Management, 21 (5), 1053-1076. https://doi.org/10.1108/JKM-03-2016-0136

Lee, H., \& Choi, B. (2003). Knowledge management enablers, processes, and organizational performance: An integrative view and empirical examination. Journal of Management Information Systems, 20(1), 179228.

Lee, J.-C., Shiue, Y.-C., \& Chen, C.-Y. (2016). Examining the impacts of organizational culture and top management support of knowledge sharing on the success of software process improvement. Computers in Human Behavior, 54, 462-474.

Lee, M. R., \& Lan, Y. C. (2011). Toward a unified knowledge management model for SMEs. Expert Systems with Applications, 38(1), 729-735.

Li, W. (2010). Virtual knowledge sharing in a cross-cultural context. Journal of Knowledge Management, 14(1), 38-50.

Lin, H. F. (2007). Knowledge sharing and firm innovation capability: an empirical study. International Journal of Manpower, 28(3/4), 315-332.

Mahmoud, M., Rasli, A. M., bin Othman, M. F., \& Abdulahad, B. M. (2014). The effect of organizational culture on knowledge sharing among academic staff holding an administrative position in university. Journal of Management Info, 3(1), 67-83.

Meirovich, G., Brender-Ilan, Y., \& Meirovich, A. (2007). Quality of hospital service: the impact of formalization and decentralization. International Journal of Health Care Quality Assurance, 20(3), 240-252. 
Mohayidin, M. G., Azirawani, N., Kamaruddin, M. N., \& Margono, M. I. (2007). The application of knowledge management in enhancing the performance of Malaysian universities. Electronic Journal of Knowledge Management, 5(3), 301-312.

Naser, S. S. A., Al Shobaki, M. J., \& Amuna, Y. M. A. (2016). Measuring knowledge management maturity at HEI to enhance performancean empirical study at Al-Azhar University in Palestine. International Journal of Commerce and Management Research, 2(5), 55-62.

Nonaka, I., Byosiere, P., Borucki, C. C., \& Konno, N. (1994). Organizational knowledge creation theory: A first comprehensive test. International Business Review, 3(4), 337-351.

Nonaka, I., \& Toyama, R. (2003). The knowledge-creating theory revisited: knowledge creation as a synthesizing process. Knowledge Management Research \& Practice, 1(1), 2-10.

Pawlowski, J. M., \& Bick, M. (2015). The global knowledge management framework: Towards a theory for knowledge management in globally distributed settings. Leading Issues in Knowledge Management, 2 (2), 134.

Rahman, M. S., Osmangani, A. M., Daud, N. M., \& AbdelFattah, F. A. M. (2016). Knowledge sharing behaviors among nonacademic staff of higher learning institutions: Attitude, subjective norms and behavioral intention embedded model. Library Review, 65(1/2), 65-83.

Ramachandran, S.D., Chong, S.C., \& Wong, K.-Y. (2013). Knowledge management practices and enablers in public universities: A gap analysis. Campus-Wide Information Systems, 30(2), 76-94.

Ramayah, T., Yeap, J. A., \& Ignatius, J. (2014). Assessing knowledge sharing among academics a validation of the Knowledge Sharing Behavior Scale (KSBS). Evaluation Review, 38(2), 160-187.

Razi, M. J. M., Karim, N. S. A., \& Mohamed, N. (2011). Knowledge management readiness measurement: Case study at institution of higher learning in Malaysia. Paper presented at the 2011 International Conference on Research and Innovation in Information Systems, (pp. 442-447), Kuala Lumpur.

Sohail, M.S., \& Daud, S. (2009). Knowledge sharing in higher education institutions: Perspectives from Malaysia. VINE, 39(2), 125-142.

Serenko, A., \& Bontis, N. (2013). The intellectual core and impact of the knowledge management academic discipline. Journal of Knowledge Management, 17(1), 137-155.

Tan, C. N.-L., \& Md. Noor, S. (2013). Knowledge management enablers, knowledge sharing and research collaboration: a study of knowledge management at research universities in Malaysia. Asian Journal of Technology Innovation, 21(2), 251-276. 
Teerajetgul, W., \& Charoenngam, C. (2006). Factors inducing knowledge creation: Empirical evidence from Thai construction projects. Engineering, Construction and Architectural Management, 13(6), 584599.

Venkatesh, V., Morris, M. G., Davis, G. B., \& Davis, F. D. (2003). User acceptance of information technology: Toward a unified view. MIS Quarterly, 425-478.

Wei Chong, C., Yen Yuen, Y., \& Chew Gan, G. (2014). Knowledge sharing of academic staff: A comparison between private and public universities in Malaysia. Library Review, 63(3), 203-223.

Willem, A., \& Buelens, M. (2009). Knowledge sharing in inter-unit cooperative episodes: The impact of organizational structure dimensions. International Journal of Information Management, 29(2), 151-160. 